\title{
Paradoxic Movement of Vocal Strings
}

\author{
Ligia Acosta*, Marisol Díaz, Eny Tamara Ramírez and Yanet Bastidas \\ HOSPITAL DE NIÑOS "J. M. de los RIOS ", Caracas Venezuela, South America
}

Submission: March 28, 2017; Published: April 07, 2017

*Corresponding author: Acosta Boett Ligia, Jefe de Servicio de Otorrinolaringología. Hospital de Niños “Dr. José Manuel de los Ríos”,

Vicepresidenta de la Junta Directiva SVORL, Venezuela, South America, Email: ligiaorl2@gmail.com

\begin{abstract}
Summary: The paradoxical movement of vocal cords is presented by alteration of the opening and closing dynamics during respiratory movements. It is characterized by the adduction of the vocal folds during inspiration, resulting in symptoms of obstructive pathology of the upper airway: stridor, respiratory distress, wheezing and dysphonia in episodic form. Its prevalence is unknown, presenting predominantly in women between 20 and 40 years. It is associated with psychological disorders, gastroesophageal reflux, structural laryngeal anomalies, laryngeal dystonia and more recently exercise and viral infections.

Case Report: A 3-year-old male preschooler with laryngeal stridor and difficulty breathing during crying and agitation from birth. At one month of age, a nasolaryngoscopic study revealed: pharyngeal hypotonia, grade I laryngomalacia, posterior laryngeal erythema and structurally normal vocal cords. He was evaluated by gastroenterology reporting Gastroesophageal reflux and indicating treatment with prokinetics. Currently with persistence and accentuation of symptoms during moderate physical activity. Nasolaryngoscopy is performed: vocal cords of normal aspect with paradoxic movement of closing during the inspiration. Phonemic rehabilitation is suggested and presents satisfactory evolution.

Conclusion: The paradoxical movement of vocal cords is a little known entity and in some cases wrongly treated. Should be suspected of exacerbated laryngeal symptoms especially with crying and physical activity. It arises as a cause of obstructive upper airway involvement in infancy. Expectant management and phonemic rehabilitation is suggested as a treatment in the alteration of the chordal dynamics.
\end{abstract}

Keywords: Paradoxical movement; Vocal cords; Episodic laryngeal dyskinetic

\section{Introduction}

The paradoxical movement of vocal cords is a dysfunction of them (CVD) defined as an anomalous movement of adduction during inspiration. This fact can lead to frequent visits to emergency services, hospitalizations and even intubations and tracheostomies, posing a therapeutic and differential diagnosis problem with some entities such as exercise-induced asthma [1].

The first descriptions that appear in the literature on CVD date back to the 1970s [2], being in 1983 when the first published series of 5 cases [3] appeared, the classic article by Christopher and Wood. This process has been referred to as «Munchausen stridor», «fictional asthma» and «emotional laryngeal stridor», and refers to an abnormal and paradoxical adduction of vocal cords during inspiration clinically with acute episodes of dyspnoea, stridor Laryngeal, dysphonia, dry cough, chest muscle straining and shallow breathing. These symptoms may also be seen in a broad spectrum of upper airway diseases such as laryngeal tumors or vocal cord polyps. However, the presentation of this condition is usually abrupt and, similarly to its disappearance, so the initial diagnosis can often be erroneously oriented as a crisis of bronchospasm, these patients sometimes receiving aggressive treatments for bronchial asthma with bronchodilators And glucocorticoids at high doses that do not improve crises with side effects such as an iatrogenic Cushing's syndrome [4].

The prevalence of this dysfunction in the population is unknown, but in 1994, in a study of the National Jewish Center for Immunology and Respiratory Medicine [5] carried out on patients diagnosed with refractory asthma, more than $10 \%$ had a CVD as the only diagnosis, while $30 \%$ of them had CVD and asthma. Most of the data published in the literature do not separate affected children from adults [6,7]. In general, CVD occurs more frequently in women between the ages of 20 and 40 , but has also been reported in males and In the pediatric population [8,9]. It is often associated with physiological and psychological risk factors. Among the former are asthma, certain brain anomalies, cystic fibrosis and gastroesophageal reflux (GER) $[8,10]$. Documented factors of psychological risk include work related to medicine, overweight, stress, anxiety, history of sexual abuse in infancy [11] or psychiatric disorders [4]. 
In the pediatric age, it is observed that the disease especially affects older children or adolescents with a good intellectual level and self-demanding with their personal performance [12]. Powell et al. [10] found that among the under 18s, women predominated $(82 \%)$ with a mean age of presentation of 14.5 years. Landwehr et al. [13] provided similar data (82\% and 14.7 years, respectively). Most are found to be athletes, with symptoms often induced by exercise and socially stressed. Powell et al. [10] also detected a strong association between MPCV and chronic GERD and stated that CVD may be a mild form of laryngospasm in response to irritation caused by reflux. In fact, GER is present in many patients with CVD, although a clear cause-effect relationship has not yet been established $[14,15]$. Finally, Powell's findings confirm that although MPCV may be linked to psychic illnesses, it is not always secondary to psychological factors as was believed.

The pathophysiology of the entity is unknown. The exact cause of this condition has not been established, but the strongest hypothesis is that by mediating the vagus nerve it can alter the laryngeal tone and lower the threshold so that a stimulus can cause a spasm in the musculaturalaringeum and produce an abnormal adduction of the folds, [16]. There are associations with entities that produce compression of the brainstem, upper or lower motor neuron syndrome. In the vast majority of patients, the mental sphere is altered from simple depression to conversational reactions. The main triggering factor associated with psychological causes is emotional stress; on the other hand, within the non-psychogenic triggers is exposure to dust, cigarette smoke, environmental and occupational irritants as well as upper respiratory infections [17].

Patients with MPCV show a wide variety of symptoms such as cough, inspiratory and expiratory wheezing, stridor and dysphonia, are typically patients who present episodic and frequent attacks with multiple admissions to emergency services treated as an asthma attack with steroids and bronchodilators even arriving to orotracheal intubations and tracheostomy. Chest x-rays do not present alterations, arterial blood gas analysis may be normal or present some degree of respiratory alkalosis; The volume flow curves are consistent with upper airway obstruction, the forced expiratory volume in the first second remains unchanged as the peak expiratory flow [18,19]. The gold diagnostic test is the direct visualization of the adductor movement of the vocal folds during the respiratory cycles, which can be done under fibrolaryngoscopy, this examination must be performed without any sedation, finding as a patognomonic sign the presence of a posterior glottic gap In diamond form.

The treatment of the entity has been well controversial and much of this is done empirically due to the lack of knowledge of its etiology. Ventilation with intermittent or continuous positive pressure opens the glottic space and decreases the Stridor, so it has been used in acute crises [18,20,21]. Benzodiazepines have been shown to be of great help not only as anxiolytics and hypnotics but also as a response to the laryngeal closure reflex response [16,20]. Percutaneous transcrichothioid injection of botulinum toxin type $\mathrm{A}$ to the intralaryngeal muscles has prevented in some patients orotracheal intubation and tracheotomy. It is still considered as experimental therapy $[18,19,22]$.

Long-term management consists of an interdisciplinary routine with psychiatry, psychology and speech therapy. The main thing is the understanding and acceptance of the pathology by the patient and his family. Many forms of psychiatric treatment have shown to be valid either to decrease the severity of an acute episode or to eliminate the possibility of future relapses, including mentioning psychodynamic and pharmacological behavioral therapies $[23,24]$. Phonemic therapy trains the patient in diaphragmatic breathing so that their conscious attention is far from the laryngeal breathing. This therapy helps the patient in the self-control of the movements of the vocal cords and manages to abort the symptoms as soon as they appear.

\section{Clinical Case}

Male preschooler of 3 years who presents stridor of larynx and respiratory difficulty during crying and agitation from birth. At one month of age, a nasolaryngoscopic study revealed: pharyngeal hypotonia, grade I laryngomalacia, posterior laryngeal erythema and structurally normal vocal cords. It was evaluated by gastroenterology reporting Gastroesophageal reflux and indicating treatment with prokinetics. Currently with persistence and accentuation of symptoms during moderate physical activity. Nasolaryngoscopy is performed: vocal cords of normal aspect with paradoxic movement of closing during the inspiration. Phonemic rehabilitation is suggested and presents satisfactory evolution.

\section{Discussion and Conclusion}

In the normal larynx the true vocal cords are separated during respiratory movements and approach during phonation, swallowing and coughing. Dysfunction of vocal cords involves the adduction of these during inspiration, which in turn causes stridor and respiratory distress.

Roger G, Denoyelle F, Garabedian EN [25], carried out a study on episodic laryngeal dysfunction in a Pediatrics department in Paris, whose findings report that the clinical manifestations of this pathology can be presented by different routes depending on the age. Thus, in newborns, it is usually associated with inspiratory stridor during crying, and the natural history is toward rapid resolution. A more severe form of presentation is with severe dyspnea and marked inspiratory stridor in those patients who generally have gastroesophageal reflux, which has not been adequately treated and enough to improve dyspnoea or associated vasovagal reflexes, and a tracheostomy can reach Be necessary. In addition, they report that it is a disease of rare presentation between 2 and 8 years. However, it may present as a form of pseudo-asthma resistant to bronchodilator and antiinflammatory drugs. 
In our patient, the onset of symptoms was from newborn and gastroesophageal reflux was also associated. In addition, the first endoscopic study performed on the patient also reports grade 1 laryngomalacia. These associated pathologies have been reported by Patel NJ et al. [26] From the ENT Department of the Medical College of Wisconsin, a study on concurrent laryngeal abnormalities in patients with dysfunction of vocal cords in 2004,30 patients, mostly female $(90 \%)$ with a mean age of 28 years (range 12 to 67 years), and an average time of evolution of the symptoms of 4.5 years [27], studied in A period of 6 months, $56 \%$ had asthma, $52 \%$ had laryngeal signs suggestive of gastroesophageal reflux, $12 \%$ had chronic laryngitis and 33\% had laryngomalacia, vocal sulcus, nodules, subglottic stenosis, vocal cord paresis, mainly in The group of those induced by exercise. They conclude that laryngeal abnormalities may be present in patients with CVD especially in those whose symptoms are induced by exercise.

CVD requires careful knowledge of differential diagnoses, their clinical characteristics, their differentiation with asthma, and the key is the complete reversibility of the patients' symptoms upon passing the acute episode. Teachers, school nurses, coaches, could be the first professionals involved in the observation of symptoms in children and adolescents, and could assume that they have asthma. The correct revision, direct visualization of the adduction of vocal cords during the nasolaryngoscopic study establishes the diagnosis. The treatment requires a multidisciplinary team, being very important to make clear the benign nature of the picture, reassuring the family, respiratory exercises and phonation techniques that seek to focus attention on exhalation and abdominal breathing are a basic pillar of the treatment. In those cases where the psychological factor plays an important role, psychotherapy can be helpful. The long-term prognosis is variable, with patients resolving the condition and others who maintain episodes over the years.

\section{References}

1. Ayres JG (1999) Pseudo-steriod resistant asthma. Thorax 54(10): 352356.

2. Patterson R, Schatz M, Horton M (1974) Munchausen's stridor: nonorganic faryngeal obstruction. Clin Allergy 4(3): 307-310.

3. Christopher KL, Word RP, Eckert C (1983) Vocal cord dysfunction presenting as asthma. N Engl J Med 308(26): 1566-1570.

4. Newman KB, Mason UG, Schmaling KB (1995) Clinical features of vocal cord dysfunction. Am J Respir Crit Care Med 152(4 Pt 1): 1382-1386.

5. Newman KB, Dubester SN (1994) Vocal Cord Dysfunction: Masquerader of asthma. Sem Resp Crit Care Med 15:161-167.

6. O'Connell MA, Sklarew PR, Goodman DL (1995) Spectrum of presentation of paradoxical Vocal cord motion in ambulatory patients. Ann Allergy Asthma Immunol 74: 341-344.

7. Morris MJ, Deal LE, Bean DR, Grbach VX, Morgan JA (1999) Vocal Cord Dysfunction in patients with exertional dysnea. Chest 116: 1676-1682.
8. Heatley DG, Swift E (1996) Paradoxical vocal cord dysfunction in an infant with stridor and gastroesophageal reflux. Int J Pediatr Otorhinolaryngol 34: 149-151.

9. Ahrens P, Seibt Y, Kitz R (2001) Vocal Cord Dysfunction in children and adolescents. Pneumologie 55: 378-384.

10. Powell DM, Karanfilov BI, Beechler KB, Treole K, Trudeau MD, et al. (2000) Paradoxical Vocal Cord Dysfunction in juveniles. Arch Otolaryngol Head Neck Surg 126: 29-34.

11. Freedman MR, Rosenberg SJ, Schmaling KB (1991) Childhood sexual abuse in patients with paradoxical vocal cord dysfunction. J Nerv Ment Dis 179: 295-298.

12. Brugman S, Howell J, Rosenberg D, Blager F, Lack G (1994) The spectrum of pediatric vocal cord dysfunction. Am Rev Respir Dis 149: 353.

13. Landwehr LP, Wood PP, Blager FB, Milgram H (1996) Vocal cord dysfunction mimicking exercice-induced bronchospasm in adolescents. Pediatrics 98: 971-974.

14. Maschka DA, Bauman NM, McCray PB, Hoffman HT, Karnell MP, et al. (1997) A classification scheme for paradoxical Vocal cord Motion. Laryngoscope 107(11 Pt 1): 1429-1435.

15. Renz V, Hern J, Tostevin P, T Hung M (2000) Wyatt functional laryngeal dyskinesia: an important cause of stridor. J Laryngol Otol 114: 790-792

16. Kevin WR, Anica Crnkovic, Steiniger JR (1998) Post-anesthesia paradoxical vocal cord motion successfully treated with midazolam. Anesthesiology 89(2): 517-519.

17. Bahrainwala AH, Simon MR (2001) Wheezing and vocal cord dysfunction mimicking asthma. Curr Opin Pulm Med 7(1): 8-13.

18. James CA (2000) Natasha Leacock-Chau all that wheezes. Current Opinion in Pediatrics 12: 213-216.

19. Maschka DA, Hoffman HT (1999) Paradoxical vocal fold motion:laryngeal asthma. Current Opinion in Otolaryngology \& Head and Neck Surgery 7(6): 339.

20. Weiss TM, Quinn FB (2001) Vocal cord dysfunction: paradoxical vocal cord motion - A thorough review grand rounds presentation, UTMB, Dept. of Otolaryngology.

21. Weir M (2002) Vocal cord dysfunction mimics asthma and may respondto heliox. Clin Pediatr 41(1): 37-41.

22. Maillard I, Schweizer V, Broccard A, Duscher A, Liaudet L, et al. (2000) Use of botulinum toxintype A to avoid tracheal intubation or tracheostomy in severeparadoxical vocal cord movement. Chest 118(3): 874-877.

23. Wynnychenko ThM, Szokol JW (2000) Paradoxical vocal cord adduction. Anesthesiology 93(3): 894-895.

24. Harbison J, Dodd J, McNicholas WT (2000) Paradoxical vocal cord motion causing stridor after thyroidectomy. Thorax 55: 533-534.

25. Roger G, Denoyelle F, Garabedian EN, Episodic laryngeal dysfuntion, Serviced ÓRL pédiatrique, hospital dénfants Armand-Trousseau, Paris, France, Europe.

26. Patel NJ, Jorgensen C, Kuhn J, Merati AL (2004) Concurrent laryngeal abnormalities in patients with paradoxical vocal Fol. Dysfunction. Otolaryngol Head Neck Surg 130(6): 686-689.

27. Duarte J, Mendoza A, Ma T García, Epidemiología de la distonía primaria. Sección de Neurología Hospital General de Segovia. 

(C) Commons Attribution 4.0 License

BY DOI: $10.19080 / \mathrm{GJ} 0.2017 .06 .555688$

\section{Your next submission with Juniper Publishers} will reach you the below assets

- Quality Editorial service

- Swift Peer Review

- Reprints availability

- E-prints Service

- Manuscript Podcast for convenient understanding

- Global attainment for your research

- Manuscript accessibility in different formats

( Pdf, E-pub, Full Text, Audio)

- Unceasing customer service

Track the below URL for one-step submission https://juniperpublishers.com/online-submission.php 